\title{
Consumo de nutrientes e parâmetros ruminais de vacas alimentadas com diferentes níveis de energia na dieta
}

[Intake of nutrients and ruminal parameters of cows fed different energy levels in the diet]

\author{
S.R. Goularte ${ }^{1,6}$, L.C.V. Ítavo ${ }^{2,7}$, M.G. Morais $^{3}$, C.C.B.F. Ítavo ${ }^{3}$, G.T. Santos ${ }^{4,7}$, A.M. Dias ${ }^{2}$, \\ F.S. Bezerra ${ }^{6,8}$, N.P. Azevedo Júnior ${ }^{6,8}$, D.S. Calvis ${ }^{6,8}$ \\ ${ }^{1}$ Aluna de pós-graduação -UCDB - Campo Grande, MS \\ ${ }^{2}$ Universidade Católica Dom Bosco - UCDB - Campo Grande, MS \\ ${ }^{3}$ Universidade Federal de Mato Grosso do Sul - Campo Grande, MS \\ ${ }^{4}$ Universidade Estadual de Maringá - Maringá, PR \\ ${ }^{5}$ Aluno de graduação - UCDB - Campo Grande, MS \\ ${ }^{6}$ Bolsista FUNDECT \\ ${ }^{7}$ Bolsista do CNPq \\ ${ }^{8}$ Bolsista PIBIC-CNPq
}

\begin{abstract}
RESUMO
Avaliou-se a influência de níveis de concentrado na dieta de bovinos. Utilizaram-se quatro vacas fistuladas no rúmen, distribuídas em quadrado latino $4 x 4$, sobre o consumo, $\mathrm{pH}$ ruminal e nitrogênio amoniacal $\left(\mathrm{N}_{-} \mathrm{NH}_{3}\right)$. Foi utilizada a silagem de milho, como volumoso, e concentrado, à base de milho, sorgo, farelo de soja, casca de soja, ureia e gordura protegida. As dietas foram isoproteicas com 18,6\% de proteína bruta, utilizando valores crescentes de extrato etéreo $(5,7 ; 6,6 ; 7,5$ e 8,4\%) para os níveis de concentrado de 30; $40 ; 50$ e $60 \%$. Os valores médios de $\mathrm{pH}$ ruminal foram 6,$71 ; 6,64 ; 6,63 ; 6,69$ e as concentrações médias de $\mathrm{N}_{-} \mathrm{NH}_{3}$ de 37,40 ; 39,$62 ; 35,59$ e $34,13 \mathrm{mg} / 100 \mathrm{~mL}$ de líquido ruminal. O tratamento com 7,5\% de extrato etéreo apresentou média de consumo de fibra detergente neutro mais alto que os demais tratamentos, com máximo consumo de matéria seca estimado em 10,47kg/dia. Dietas com gordura protegida não interferiram no ambiente ruminal, até níveis de $8,4 \%$ de extrato etéreo, apresentando melhor eficiência com relação ao consumo de $55 \%$ de concentrado.
\end{abstract}

Palavras-chave: vaca de leite, rúmen, extrato etéreo, nível de concentrado, $\mathrm{pH}$ ruminal, nitrogênio amoniacal

\begin{abstract}
The influence of concentrate levels in the diet of cattle on intake, rumen $\mathrm{pH}$, and ammonia nitrogen (NH3-N) using four cows fistulated in the rumen and distributed in $4 \times 4$ Latin square was evaluated. Corn silage was used as roughage and concentrate was maize, sorghum, soybean hulls, soybean rules, urea, and protected fat. Diets were isonitrogenous with $18.6 \%$ crude protein, using increasing amounts of ether extract (5.7, 6.6, 7.5, and $8.4 \%$ ) to the levels of concentrate, 30, 40, 50 and 60\%. The average values of rumen pH were 6.71, 6.64, 6.63, and 6.69 and the average concentrations of $\mathrm{NH3}-\mathrm{N}$ were 37.40, 39.62, 35.59, and 34.13mg/100mL of rumen fluid. Animals fed $7.5 \%$ ether extract diet had higher neutral detergent fiber intake than the animals of other treatments with maximum dry matter intake estimated in 10.47kg/day. Protected fat diet did not interfere in the environment of rumen up to levels of $8.4 \%$ of ether extract, providing better efficiency with respect to intake of $55 \%$ concentrate.
\end{abstract}

Keywords: dairy cows, rumen, ammonia-N, concentrate level, ether extract, ruminal $p H$

\section{INTRODUÇÃO}

A alimentação de bovinos é baseada no fornecimento de volumoso, o que pode ser limitante à produtividade, devido à baixa concentração de nutrientes por unidade de massa e de lenta taxa de degradação e escape, com restrição à ingestão de alimento (Jung e Allen, 1995). Neste sentido, o consumo de energia é determinado pela concentração energética e pela

Recebido em 14 de janeiro de 2009

Aceito em 22 de fevereiro de 2010

E-mail: sandra.goularte@gmail.com 
taxa de ingestão da dieta e constitui-se em fator importante para produção de leite e carne, devido à interferência no consumo de forragem e na digestibilidade da matéria seca, bem como na eficiência da utilização da própria forragem.

No início da lactação, os animais de alta produção não atingem um consumo de alimento suficiente para o atendimento das exigências energéticas (Lopez et al., 2004). Na tentativa de suprir suas exigências, vacas de alta produção mobilizam tecidos corporais, particularmente os depósitos de gordura, resultando em perda de peso e de condição corporal (Nutrient..., 2001), além de possibilitar, muitas vezes em intercorrências como cetose. Uma das alternativas para o aumento da densidade energética da ração é a utilização de grãos, os quais podem ocasionar problemas de ordem digestiva e metabólica, como redução na digestão da fibra, acidose, laminite, inadequada secreção de saliva para manutenção do $\mathrm{pH}$ ruminal entre 6 e 7 e estímulo da motilidade ruminal, com consequências negativas para a digestão de proteína, celulose, hemicelulose e pectina, com menor efeito sobre o amido (Hoover e Stokes, 1991).

Dessa maneira, a substituição de amido por gordura seria um método eficiente para o incremento da densidade energética, sem comprometimento da fermentação da fibra da dieta, e minimizaria os problemas ocasionados nos animais submetidos à alta concentração de grãos na ração (Silva, 2005). No caso de vacas leiteiras de alta produção, a adição de gordura à dieta também pode aumentar a produção de leite, pois influencia diretamente alguns parâmetros ruminais relacionados ao máximo aproveitamento dos alimentos pelos ruminantes (Ítavo e Ítavo, 2005).

Como o pH ruminal está diretamente relacionado aos produtos finais da fermentação e à taxa de crescimento dos microrganismos ruminais, a sua estabilidade é atribuída, em parte, à saliva, que possui alto poder tamponante, e à capacidade da mucosa ruminal em absorver os ácidos graxos voláteis produzidos na fermentação ruminal (Van Soest, 1994), o que constitui importante parâmetro a ser avaliado em experimentos da área de nutrição de ruminantes.

Russell et al. (1992) afirmaram, a despeito do tamponamento via saliva, que o $\mathrm{pH}$ ruminal pode decrescer, pela restrição da quantidade de fibra da dieta ou acréscimo de carboidratos rapidamente fermentáveis. Desta forma, o $\mathrm{pH}$ ruminal tem recebido atenção considerável para as explicações das reduções na ingestão e digestibilidade de volumosos, resultantes da suplementação energética (Ítavo et al., 2002).

A presença de nitrogênio amoniacal no líquido ruminal é fator preponderante no desenvolvimento da microflora do rúmen (Van Soest, 1994). A amônia ruminal é proveniente do nitrogênio não-proteico da dieta, da degradação da proteína verdadeira dietética e da reciclagem via saliva ou difusão pela parede ruminal. Sua remoção pode ser realizada na incorporação em proteína microbiana, pela passagem ao trato posterior ou absorção ruminal.

Os lipídios podem interromper a fermentação ruminal, sendo que a degradação de carboidratos estruturais pode ser reduzida em $50 \%$ ou mais, com adição de menos do que $10 \%$ de gordura (Jenkins e Palmquist, 1984). Tal redução é acompanhada pela diminuição da produção de metano, hidrogênio, ácidos graxos voláteis e da relação acetato:propionato (Boggs et al., 1987; Chalupa et al., 1984).

Bernardes et al. (2007), ao fornecerem caroço de algodão a bezerros, com 90 dias de idade, observaram o pH ruminal semelhante ao de um animal adulto e demonstraram que o caroço de algodão foi capaz de manter o $\mathrm{pH}$ ruminal na faixa favorável ao crescimento de bactérias celulolíticas. A relação acetato:propionato aumentou com a idade, provavelmente em função da maior capacidade absortiva do rúmen, devido ao aumento do compartimento e tamponamento do ambiente ruminal, sem influência da dieta à base de caroço de algodão.

Os efeitos variáveis de fontes lipídicas na fermentação ruminal normalmente são atribuídos a diferenças básicas na estrutura dos lipídios. Um dos fatores é o grau de insaturação, pois ácidos graxos insaturados possuem maior inibição sobre a fermentação, quando comparado a ácidos graxos saturados (Palmquist e Jenkins, 1980; Chalupa et al., 1984). A presença de grupo carboxila livre é um fator importante no processo de inibição da fermentação ruminal, pois derivados de ácidos graxos, como sais de cálcio de ácidos graxos de cadeia longa (Jenkins e 
Palmquist, 1982) e triglicerídeos (Chalupa et al., 1984), inibem menos a fermentação quando comparados a ácidos graxos livres, podendo ser uma alternativa para aumentar a densidade de dietas.

Altas concentrações de triacilglicerois na dieta aumentam o conteúdo de lipídio total no rúmen, entretanto o aumento correspondente no pool ruminal de ácidos graxos insaturados livres pode ser menor se a lipólise e a bio-hidrogenação forem diminuídas. Todavia, alguns estudos revelaram que as taxas de lipólise e biohidrogenação são alteradas substancialmente pela maturidade da forragem, conteúdo de nitrogênio e tamanho da partícula (Jenkins, 1993). Já o grau de formação de sais de carboxilato depende da solubilidade do cálcio dietético, conteúdo de lipídios da dieta, pH ruminal e saturação das cadeias dos ácidos graxos (Jenkins e Palmquist, 1982).

A investigação atual e a prática demonstram que 3 a $5 \%$ de gordura podem ser adicionados às dietas para aumentar a ingestão de energia por vacas de alta produção e/ou reduzirem amido na alimentação, aumentando, assim, a razão de forragem para concentrado, evitando a depressão da gordura do leite (Palmquist e Jenkins, 1980). Segundo Salla et al. (2003), a utilização de gordura suplementar, sob as formas protegida ou saturada, aumentou a produção de leite corrigido a $4 \%$ de gordura, sem, no entanto, influenciar a ingestão de alimentos pelos animais.

Segundo Haaland et al. (1981), dietas contendo mais de $5 \%$ de gordura não protegida da degradação ruminal reduzem a ingestão de alimento, prejudicando o desempenho de animais nas fases de crescimento e terminação. Um aumento da quantidade de gordura da dieta maximiza a influência dos lipídeos sobre a fermentação ruminal. Em geral, os efeitos de uma variedade de ácidos graxos voláteis no rúmen e/ou a proporção de acetato:propionato são mínimos quando incluídos abaixo de $5 \%$ da MS (Grummer, 1995). Entretanto, são poucos os relatos sobre o aumento do nível de extrato etéreo em dietas, por meio do uso de gordura protegida e sua relação com parâmetros ruminais, como $\mathrm{pH}$ e $\mathrm{N}-\mathrm{NH}_{3}$.
Este trabalho teve por objetivo avaliar a influência de diferentes níveis de extrato etéreo em dietas isoproteicas por meio de medidas de consumo, $\mathrm{pH}$ e nitrogênio amoniacal ruminal, com estimativa da melhor relação volumoso:concentrado na dieta.

\section{MATERIAL E MÉTODOS}

Foram utilizadas quatro vacas leiteiras, em sistema tie stall, fistuladas no rúmen, com peso médio de $442,15 \mathrm{~kg}$. O ensaio foi dividido em quatro períodos experimentais, de 10 dias, compreendendo sete dias de adaptação à dieta e três dias de coleta, totalizando 40 dias de ensaio, em quadrado latino $4 \times 4$ (quatro tratamentos e quatro períodos).

As vacas permaneceram estabuladas, com água à vontade e arraçoamento uma vez ao dia, de forma a manter as sobras em torno de $5 \%$ do fornecido, em base de matéria seca. Durante o período de coleta, medidas de consumo de nutrientes foram realizadas diariamente. As dietas fornecidas e as sobras foram coletadas para elaboração de amostras compostas por animal e por período, as quais foram submetidas às análises laboratoriais para a determinação de matéria seca (MS), proteína bruta (PB), extrato etéreo (EE) e fibra em detergente neutro (FDN), segundo metodologias descritas por Silva e Queiroz (2002).

Os tratamentos consistiram na variação da relação volumoso:concentrado 70:30; 60:40; 50:50 e 40:60, com base na matéria seca, a fim de se obterem níveis crescentes de extrato etéreo $(5,7 ; 6,6 ; 7,5$ e $8,4 \%)$, para os níveis de concentrado. A composição das dietas experimentais é apresentada na Tab.1.

As dietas foram isoproteicas, utilizando-se ureia pecuária como fonte suplementar de nitrogênio para o alcance de $18,6 \%$ PB. O volumoso utilizado foi silagem de milho, e o concentrado à base de milho, sorgo, farelo de soja, casca de soja, suplemento mineral, ureia e gordura protegida (Tab. 1). 
Tabela 1. Composição percentual de ingredientes e teores de matéria seca (MS), matéria orgânica (MO), proteína bruta $(\mathrm{PB})$, extrato etéreo (EE), fibra em detergente neutro (FDN) e nutrientes digestíveis total (NDT), em função do nível de concentrado na dieta

\begin{tabular}{lcccc}
\hline & \multicolumn{4}{c}{ Nível de concentrado (\%) } \\
\cline { 2 - 4 } Nutriente & 30 & 40 & 50 & 60 \\
\cline { 2 - 4 } Silagem de milho & \multicolumn{3}{c}{ Composição da dieta (\% MS) } \\
\cline { 2 - 4 } Concentrado $^{1}$ & 68,69 & 59,36 & 49,71 & 40,08 \\
Ureia & 29,67 & 39,54 & 49,74 & 59,82 \\
& 1,64 & 1,10 & 0,55 & 0,00 \\
\hline MS (\%) & 43,13 & 46,34 & 54,56 \\
MO (\%MS) & 94,91 & 95,77 & 50,18 & 98,65 \\
PB (\%MS) & 18,60 & 18,60 & 96,06 & 18,60 \\
EE (\%MS) & 5,70 & 6,60 & 18,60 & 8,40 \\
FDN (\%MS) & 45,76 & 42,55 & 7,50 & 36,12 \\
\hline NDT $(\% M S)$ & 71,10 & 74,82 & 39,33 & 83,57 \\
\hline
\end{tabular}

${ }^{\mathrm{T}}$ Concentrado: farelo de soja(46\%) - 27\%; milho grão moído - 20\%; casca de soja - 20\%; sorgo grão moído - 20\%; gordura protegida $-9,5 \%$; ureia - $2 \%$ e núcleo mineral aditivado - $2 \%$

${ }^{a}$ Weiss et al. (1992).

No último dia de cada período experimental, foram realizadas colheitas de líquido ruminal, para determinação do $\mathrm{pH}$ e concentrações de nitrogênio amoniacal $\left(\mathrm{N}-\mathrm{NH}_{3}\right)$, com início antes do fornecimento da dieta, tomado como tempo zero (0), e 1, 2, 3, 4, 5, 6, 7, 8, 9, 10, 11 e 12 horas após a alimentação.

O material coletado foi filtrado em camadas de gaze a fim de se obterem $100 \mathrm{~mL}$ de líquido ruminal. Imediatamente, foi determinado o $\mathrm{pH}$ em potenciômetro digital, e em seguida, adicionado $1 \mathrm{~mL}$ de solução de ácido clorídrico (HCl) 1:1. As amostras foram armazenadas em recipientes plásticos a $5^{\circ} \mathrm{C}$. Para a determinação da concentração de nitrogênio amoniacal, foi utilizado o método adaptado semimicro Kjedhal, usando $10 \mathrm{~mL}$ de ácido bórico $4 \%$ e indicador misto e ácido clorídrico $0,1 \mathrm{~N}$ para titulação. Os dados foram avaliados por meio de análise de variância e regressão, adotando $5 \%$ de probabilidade.

\section{RESULTADOS E DISCUSSÃO}

Os consumos médios diários de MS, matéria orgânica (MO), PB, EE, FDN e nutrientes digestíveis totais (NDT), em função dos tratamentos, são apresentados na Tab. 2. Houve aumento linear dos consumos em $\mathrm{kg} / \mathrm{dia}$ de MS, $\mathrm{PB}$, EE e NDT em função do nível de concentrado.

Caton e Dhuyvetter (1997) citaram que o fornecimento de concentrados com alto teor de energia reduz o consumo de volumoso. Em muitas situações, o consumo é positivamente correlacionado à digestibilidade da dieta, influenciada pelas quantidades de elementos indigestíveis e parede celular (Ítavo e Ítavo, 2005).

O consumo de FDN apresentou-se de forma quadrática com máximo obtido em $53,71 \%$ de concentrado, o que corresponde ao consumo de MS de $10,47 \mathrm{~kg} / \mathrm{dia}$. Os resultados sugerem que dietas com, no máximo, 54\% de concentrado seriam as mais indicadas para maximização de consumo com menor possibilidade de ocorrência de distúrbios metabólicos, possivelmente traduzindo-se em melhor desempenho. Segundo Ítavo e Ítavo (2004), a maximização do consumo de MS visa ao aumento da ingestão de energia, o que pode ser obtido pelo aumento do nível de concentrados e introdução de gordura na dieta. 
Tabela 2. Consumo de matéria seca (MS), proteína bruta (PB), extra etéreo (EE), nutrientes digestíveis total (NDT), fibra em detergente neutro (FDN), em kg/dia, \% PV, g/kg PV ${ }^{0,75}$ de vacas alimentadas com dietas contendo diferentes níveis de concentrado

\begin{tabular}{|c|c|c|c|c|c|c|}
\hline \multirow{2}{*}{ Consumo } & \multicolumn{4}{|c|}{ Nível de concentrado na dieta (\%) } & \multirow{2}{*}{$\mathrm{CV}(\%)$} & \multirow{2}{*}{$r^{2}$} \\
\hline & 30 & 40 & 50 & 60 & & \\
\hline $\mathrm{MS}^{\mathrm{a}}(\mathrm{kg} / \mathrm{dia})$ & 8,28 & 9,28 & 10,39 & 10,86 & 9,03 & 0,98 \\
\hline $\mathrm{MS}^{\mathrm{b}}(\% \mathrm{PV})$ & 1,87 & 2,08 & 2,39 & 2,44 & 9,00 & 0,94 \\
\hline $\operatorname{MS}^{\mathrm{c}}\left(\mathrm{g} / \mathrm{kg} \mathrm{PV}^{0,75}\right)$ & 85,76 & 95,56 & 109,00 & 112,11 & 9,01 & 0,95 \\
\hline $\mathrm{PB}^{\mathrm{d}}(\mathrm{kg} / \mathrm{dia}, \% \mathrm{PV})$ & 1,45 & 1,66 & 1,91 & 2,07 & 5,31 & 0,99 \\
\hline $\mathrm{EE}^{\mathrm{e}}\left(\mathrm{kg} / \mathrm{dia}, \mathrm{g} / \mathrm{kgPV}^{0,75}\right)$ & 0,42 & 0,54 & 0,67 & 0,80 & 5,61 & 0,99 \\
\hline $\operatorname{NDT}^{f}(k g / d i a)$ & 5,89 & 6,91 & 8,10 & 8,97 & 5,37 & 0,99 \\
\hline $\mathrm{NDT}^{\mathrm{g}}(\% \mathrm{PV})$ & 1,33 & 1,55 & 1,86 & 2,02 & 5,23 & 0,99 \\
\hline $\left.\mathrm{NDT}^{\mathrm{h}} \mathrm{g} / \mathrm{kg} \mathrm{PV}^{0,75}\right)$ & 60,97 & 71,25 & 84,92 & 92,57 & 5,26 & 0,99 \\
\hline $\mathrm{FDN}^{\mathrm{i}}(\mathrm{kg} / \mathrm{dia})$ & 3,76 & 3,96 & 4,14 & 4,08 & 5,04 & 0,97 \\
\hline $\mathrm{FDN}^{\mathrm{j}}(\% \mathrm{PV})$ & 0,85 & 0,89 & 0,95 & 0,92 & 4,95 & 0,87 \\
\hline $\mathrm{FDN}^{\mathrm{k}}\left(\mathrm{g} / \mathrm{kg} \mathrm{PV}^{0,75}\right)$ & 38,86 & 40,79 & 43,45 & 42,10 & 4,97 & 0,90 \\
\hline
\end{tabular}

$\mathrm{PV}=$ peso vivo; $\mathrm{n}=$ nível de concentrado.

${ }^{\mathrm{a}} \mathrm{Y}=5,71911+0,088521 . \mathrm{n} ;{ }^{\mathrm{b}} \mathrm{Y}=1,28299+0,0203089 . \mathrm{n} ;{ }^{\mathrm{c}} \mathrm{Y}=58,9844+0,924953 . \mathrm{n}$;

${ }^{\mathrm{d}} \mathrm{Y}=0,815677+\quad 0,0212571 . \mathrm{n} ; \quad{ }^{\mathrm{e}} \mathrm{Y}=0,0357931+\quad 0,0127037 . \mathrm{n} ;{ }^{\mathrm{f}} \mathrm{Y}=\quad 2,78025+$ 0,104189.n;

${ }^{\mathrm{g}} \mathrm{Y}=0,621182+0,0237635 . \mathrm{n} ;{ }^{\mathrm{h}} \mathrm{Y}=28,6096+1,08480 . \mathrm{n} ;{ }^{\mathrm{i}} \mathrm{Y}=2,19850+0,0714695 . \mathrm{n}-0,000665322 . \mathrm{n}^{2}$;

${ }^{\mathrm{j}} \mathrm{Y}=0,421554+0,0196221 . \mathrm{n}-0,000187393 . \mathrm{n}^{2} ;{ }^{k} \mathrm{Y}=20,1344+0,862217 . \mathrm{n}-0,00820287 . \mathrm{n}^{2}$;

Os consumos de matéria seca $(\mathrm{kg} / \mathrm{dia}$; \% PV e $\mathrm{g} / \mathrm{kg}$ de $\mathrm{PV}^{0,75}$ ) aumentaram linearmente com o aumento de concentrado na dieta, à semelhança dos resultados obtidos por Vargas Jr. et al. (2002). A maior ingestão de nutrientes ocorreu com o aumento da energia da dieta. Entretanto, o comportamento do consumo de fibra em detergente neutro (FDN) apresentou-se de forma quadrática, também observada por Putrino et al. (2007). Segundo Ítavo et al. (2002), tal fato é esperado, uma vez que a porcentagem de FDN reduz com o aumento da quantidade de concentrado na dieta.

No trabalho de Salla et al. (2003), com vacas no início de lactação, os níveis de extrato etéreo consumidos foram de 3,7, 6,7 e 6,3\% da matéria seca, respectivamente para as dietas controle, gordura protegida e grão de soja. Embora os níveis de extrato etéreo fossem maiores do que os usualmente recomendados (em torno de 5\%), aparentemente estes não exerceram efeito negativo pronunciado sobre a digestibilidade do volumoso, e, consequentemente, sobre o consumo voluntário, assemelhando-se aos resultados apresentados na Tab. 2. Outro aspecto a considerar é que, aparentemente, as fontes de gordura adicionadas foram palatáveis ou pelo menos não alteraram negativamente o apetite dos animais.

As médias dos valores de $\mathrm{pH}$ ruminal foram 6,$71 ; 6,64 ; 6,63 ; 6,69$ para os níveis de concentrado $30,40,50,60 \%$, respectivamente
(Tab. 3), indicando que não houve acidificação com o aumento do nível de energia proveniente do extrato etéreo (gordura protegida), semelhantes aos resultados de Caton e Dhuyvetter (1997), que apresentaram, em revisão, resultados de pesquisas indicando que o $\mathrm{pH}$ ruminal não é sempre reduzido pela suplementação. Mould et al. (1983) observaram que o efeito do $\mathrm{pH}$ na digestão da fibra é bifásico, assim, a redução de 6,8 para 6,0 provoca depressão na digestão da fibra e somente abaixo de 6,0 ocorre efeito drástico. Russel et al. (1979) indicaram que a população de bactérias celulolíticas diminuiu quando o $\mathrm{pH}$ variou de 5,7 a 6,2 , enquanto as bactérias fermentadoras de carboidratos solúveis persistem até em variações de $\mathrm{pH}$ de 4,6 a 4,9. Mudanças nas populações bacterianas em resposta à redução de $\mathrm{pH}$ têm sido sugeridas como uma das razões para redução na ingestão e digestão de forragem por ruminantes alimentados com dietas à base de forragens. Semelhantes resultados foram publicados por Ítavo et al. (2002), ao trabalharem com novilhos em diferentes níveis de concentrado.

Na Tab. 3, mostram-se as médias e coeficientes de variação de $\mathrm{pH}$ no líquido ruminal dos diferentes níveis de concentrado utilizados em função do tempo. $\mathrm{O}$ valor máximo de concentrado encontrado para otimização do $\mathrm{pH}$ foi de $53,51 \%$. 
Tabela 3. Médias e coeficientes de variação do $\mathrm{pH}$ no líquido ruminal de vacas alimentadas em relação aos níveis de concentrado (n), e tempo (t) pós-alimentação

\begin{tabular}{|c|c|c|c|c|c|}
\hline \multirow{2}{*}{$\begin{array}{l}\text { Tempo } \\
\text { (horas) }\end{array}$} & \multicolumn{4}{|c|}{ Nível de concentrado (\%) } & \multirow[t]{2}{*}{$\mathrm{CV}(\%)$} \\
\hline & 30 & 40 & 50 & 60 & \\
\hline 0 & 7,04 & 6,91 & 6,91 & 6,92 & 2,97 \\
\hline 1 & 6,98 & 6,91 & 6,82 & 6,86 & 2,87 \\
\hline 2 & 6,92 & 6,81 & 6,78 & 6,77 & 2,92 \\
\hline 3 & 6,87 & 6,72 & 6,72 & 6,73 & 2,43 \\
\hline 4 & 6,84 & 6,66 & 6,66 & 6,67 & 2,87 \\
\hline 5 & 6,69 & 6,61 & 6,61 & 6,63 & 3,42 \\
\hline 6 & 6,56 & 6,48 & 6,59 & 6,63 & 4,09 \\
\hline 7 & 6,64 & 6,50 & 6,55 & 6,71 & 3,42 \\
\hline 8 & 6,56 & 6,54 & 6,53 & 6,68 & 3,85 \\
\hline 9 & 6,51 & 6,52 & 6,52 & 6,64 & 3,32 \\
\hline 10 & 6,50 & 6,47 & 6,52 & 6,59 & 3,63 \\
\hline 11 & 6,58 & 6,57 & 6,43 & 6,56 & 2,74 \\
\hline 12 & 6,53 & 6,58 & 6,58 & 6,64 & 3,21 \\
\hline $\mathrm{CV}(\%)$ & 2,45 & 2,23 & 2,67 & 4,86 & 3,23 \\
\hline
\end{tabular}

$\mathrm{CV}=$ Coeficiente de variação $(\%)$

$\mathrm{Y}=7,81348-0,0345728 . \mathrm{n}+0,000329899 . \mathrm{n}^{2}-0,119204 . \mathrm{t}+0,00440061 . \mathrm{t}^{2}+0,000731593 . n . \mathrm{t}\left(\mathrm{r}^{2}=0,91\right)$

As concentrações médias de $\mathrm{N}-\mathrm{NH}_{3}$ observadas foram 37,$40 ; 39,62 ; 35,59$ e $34,13 \mathrm{mg} / 100 \mathrm{~mL}$ de líquido ruminal para os níveis de concentrados $30,40,50$ e $60 \%$, respectivamente (Tab. 4). O mínimo de concentrado encontrado para o máximo de $\mathrm{N}-\mathrm{NH}_{3}$ foi $31,8 \%$. Houve interação entre tempo e concentrado para os teores de nitrogênio amoniacal. $\mathrm{O}$ nível médio de $\mathrm{N}-\mathrm{NH}_{3}$ observado foi maior aos 26,06mg/100mL, também encontrados por Veloso et al. (2000), ao trabalharem com novilhos mestiços, avaliando a relação folhas:hastes e a degradabilidade no rúmen, da fibra em detergente neutro e da fibra em detergente ácido de forrageiras tropicais.

Satter e Slyter (1974) estabeleceram que $5 \mathrm{mg}$ $\mathrm{N} / 100 \mathrm{~mL}$ de fluido ruminal constitui o mínimo ideal para ocorrência de fermentação microbiana ruminal. Leng (1990) relatou que, em condições tropicais, são necessárias concentrações de $\mathrm{N}$ maiores do que $10 \mathrm{mg} / \mathrm{dL}$, para que haja maximização da digestão ruminal da matéria seca, e maiores do que $20 \mathrm{mg} / \mathrm{dL}$, para que ocorra a maximização do consumo. Mehrez et al. (1977) afirmaram que o máximo de atividade fermentativa ruminal é obtido quando o $\mathrm{N}$ amoniacal alcança valores entre 19 e $23 \mathrm{mg}$ N/100mL de líquido ruminal, e Van Soest (1994) citou como nível ótimo $10 \mathrm{mg} / 100 \mathrm{~mL}$. Nesse sentido, verifica-se que os teores de $\mathrm{N}$-amoniacal obtidos neste ensaio são mais altos que os recomendados pela literatura.

Destaca-se que níveis elevados de $\mathrm{N}$-amoniacal podem significar maiores perdas de nitrogênio no sistema, uma vez que, para haver síntese de proteína microbiana e, consequentemente, aproveitamento do $\mathrm{N}$-amoniacal, deverá existir disponibilidade de esqueletos de carbono em sincronia com degradação da proteína no rúmen, o que não ocorre em dietas com teores de amido e CNE reduzidos e/ou com fontes de energia provenientes de lipídios, o que deve acarretar perda de energia, na forma de ATP, para transformação em ureia pelo fígado, para excreção urinária. 
Consumo de nutrientes e parâmetros...

Tabela 4. Médias das concentraç̃oes de N-NH3 (mg/100 mL de amostra) no líquido ruminal em relação aos níveis de concentrado, e tempo (horas) pós-alimentação

\begin{tabular}{|c|c|c|c|c|c|}
\hline \multirow{2}{*}{$\begin{array}{l}\text { Tempo } \\
\text { (horas) }\end{array}$} & \multicolumn{4}{|c|}{ Nível de concentrado (\%) } & \multirow[t]{2}{*}{$\mathrm{CV}(\%)$} \\
\hline & 30 & 40 & 50 & 60 & \\
\hline 0 & 36,10 & 45,79 & 46,47 & 48,27 & 29,21 \\
\hline 1 & 53,69 & 57,21 & 59,63 & 47,13 & 19,47 \\
\hline 2 & 55,52 & 56,77 & 45,95 & 38,48 & 13,86 \\
\hline 3 & 48,40 & 49,93 & 46,41 & 31,69 & 13,63 \\
\hline 4 & 40,95 & 43,73 & 28,58 & 32,12 & 22,90 \\
\hline 5 & 38,08 & 39,98 & 28,60 & 30,94 & 20,45 \\
\hline 6 & 33,94 & 28,33 & 28,78 & 31,10 & 27,54 \\
\hline 7 & 32,56 & 27,57 & 28,44 & 35,62 & 30,82 \\
\hline 8 & 32,98 & 38,41 & 34,31 & 31,22 & 27,77 \\
\hline 9 & 33,46 & 33,45 & 29,08 & 33,93 & 32,72 \\
\hline 10 & 28,88 & 35,63 & 29,32 & 28,00 & 27,53 \\
\hline 11 & 24,94 & 29,76 & 28,88 & 28,00 & 22,54 \\
\hline 12 & 26,69 & 28,57 & 28,19 & 27,13 & 19,74 \\
\hline$(\%)$ & 21,50 & 26,56 & 19,20 & 26,39 & 23,73 \\
\hline
\end{tabular}

$\mathrm{CV}=$ Coeficiente de variação $(\%)$

$\mathrm{Y}=45,6308-0,564924 . \mathrm{n}+0,00921559 . \mathrm{n}^{2}-4,52422 . \mathrm{t}+0,138531 . \mathrm{t}^{2}+0,0209805 . n \cdot \mathrm{t}\left(\mathrm{r}^{2}=0,92\right)$

\section{CONCLUSÕES}

Os níveis de concentrado na dieta de vacas confinadas influenciaram linearmente o consumo de nutrientes (matéria seca, proteína bruta, extrato etéreo e nutrientes digestíveis totais) e, quadraticamente, o consumo de FDN. Dietas com gordura protegida não interferem no ambiente ruminal até níveis de $60 \%$ de concentrado, mas para melhor eficiência de consumo, sugere-se que o nível de concentrado na dieta não ultrapasse a $55 \%$ da matéria seca.

\section{REFERÊNCIAS BIBLIOGRÁFICAS}

BERNARDES, E.B.; COELHO, S.G.; CARVALHO, A.U. et al. Efeito da substituição do feno de Tifton 85 pelo caroço de algodão como fonte de fibra na dieta de bezerros. Arq. Bras. Med. Vet. Zootec., v.59, p.955-964, 2007.

BOGGS, D.L.; BERGEN, W.G.; HAWKINS, D.R. Effects of tallow supplementation and protein withdrawal on ruminal fermentation, microbial synthesis and site of digestion. J. Anim. Sci., v.64, p.970-976, 1987.

CATON, J.S.; DHUYVETTER, D.V. Influence of energy supplementation on grazing ruminants: Requirements and responses. J. Anim. Sci., v.75, p.533-542, 1997.
CHALUPA, W.B.; RICKABAUGH, D.S.; KRONFELD, $S$. et al. Rumen fermentation in vitro as influenced by long chain fatty acids. J. Dairy Sci., v.67, p.1439-1446, 1984.

GRUMMER, R.R. Impact of changes in organic nutrient metabolism on feeding the transition dairy cow. J. Anim. Sci., v.73, p.2820-2833, 1995.

HAALAND, G.L.; MATSUSHIMA, J.K.; JOHNSON, D.E. et al. Effect of replacement of corn by protected tallow in a cattle finishing diet on animal performance and composition. J. Anim. Sci., v.52, p.696, 1981.

HOOVER, W.H.; STOKES, S.R. Balancing carbohydrates and proteins for optimum rumen microbial yield. J. Dairy Sci., v.74, p.3630-3644, 1991.

ÍTAVO, L.C.V.; ÍTAVO, C.C.B.F. Aspectos relacionados à produção de leite. In: SILVA, M.J. (Ed.). Métodos e culturas alternativas na agricultura familiar. 2.ed. Campo Grande: UCDB, 2004. p.185-214.

ÍTAVO, L.C.V.; ÍTAVO, C.C.B.F. Parâmetros ruminais e suas correlações com desempenho, consumo e digestibilidade em ruminantes. In: ÍTAVO, L.C.V.; ÍTAVO, C.C.B.F (Eds). Nutrição de ruminantes: Aspectos relacionados à digestibilidade e ao aproveitamento de nutrientes. Campo Grande: UCDB, 2005. p.49-72. 
ÍTAVO, L.C.V.; VALADARES FILHO, S.C.; SILVA, F.F. et al. Níveis de Concentrado e Proteína Bruta na Dieta de Bovinos Nelore nas Fases de Recria e Terminação: Consumo e Digestibilidade. Rev. Bras. Zootec., v.31, supl.2, p.1033-1041, 2002.

JENKINS, T.C. Lipid metabolism in the rumen. $J$. Dairy Sci., v.76, p.3851-3863, 1993.

JENKINS, T.C.; PALMQUIST, D.L. Effect of added fat and calcium on in vitro formation of insoluble fatty acid soaps and cell wall digestibility. J. Anim. Sci., v.55, p.957-963, 1982.

JENKINS, T.C.; PALMQUIST, D.L. Effect of fatty acids or calcium soaps on rumen and total nutrient digestibility of dairy rations. J. Dairy Sci., v.67, p.978983, 1984.

JUNG, H.G.; ALLEN, M.S. Characteristics of plant cell walls affecting intake and digestibility of forage by ruminants. J. Anim. Sci., v.73, p.2774-2790, 1995.

LENG, R.A. Factors affecting the utilization of "poorquality" forages by ruminants particularly under tropical conditions. Nutr. Res. Rev., v.3, p.277-303, 1990.

LOPEZ, S. E.; LÓPEZ, J.; STUMPF JUNIOR, W. Parâmetros séricos de vacas leiteiras na fase inicial de lactação, suplementadas com diferentes fontes de gordura. Assoc. Latinoam. Prod. Anim., v.12, p.96102, 2004.

MEHREZ, A.Z.; ÆRSKOV, E.R.; McDONALD, I. Rates of rumen fermentation in relation to ammonia concentration. Br. J. Nutr., v.38, p.437-443, 1977.

MOULD, F.L.; ØRSKOV, E.R.; MANN, S.O. Associative effects of mixed feeds. 2.The effect dietary additions of bicarbonate salts on the voluntary intake and digestibility of diets containing various proportions of hay and barley. Anim. Feed Sci. Technol., v.10, p.15-23, 1983.

NUTRIENT requirements of dairy cattle. 7 ed. Washington: National Academy, 2001, 381p.

PALMQUIST, D.L. Influence of source and amount of dietary fat on digestibility in lactating cows. $J$. Dairy Sci., v.74, p.1354-1361, 1991.

PALMQUIST, D.L., JENKINS, T.C. Fat in lactation rations: review. J. Dairy Sci., v.63, p.1-9, 1980.

PUTRINO, S.M.; LEME, P.R.; SILVA, S.L. et.al. Digestibilidade aparente de dietas com níveis crescentes de concentrado em novilhos Brangus e Nelore. Arq. Bras. Med. Vet. Zootec., v.59, p.406-413, 2007.
RUSSELL, J.B.; O'CONNOR, J.D.; FOX, D.J. et al. A net carbohydrate and protein system for evaluating cattle diets: I ruminal fermentation. J. Anim. Sci., v.70, p.3551-3561, 1992.

RUSSELL, J.B.; SHARP, W.M.; BALDWIN, R.L. The effect of $\mathrm{pH}$ on maximum bacterial growth rate and its possible role as a determinant of bacterial competition in the rumen. J. Anim. Sci., v.48, p.251, 1979.

SALLA, L.E.; FISCHER, V.; FERREIRA E.X. et. al. Comportamento ingestivo de vacas Jersey alimentadas com dietas contendo diferentes fontes de gordura nos primeiros 100 dias de lactação. Rev. Bras. Zootec., v.32, p.683-689, 2003.

SATTER, L.D.; SLYTER, L.L. Effect of ammonia concentration on rumen microbial protein production in vitro. Br. J. Nutr., v.32, p.199-208, 1974.

SILVA, D.J., QUEIROZ, A.C. Análise de alimentos: métodos químicos e biológicos. Viçosa: UFV, 2002.

SILVA, S.L. Milho grão seco, grão úmido e sais de cálcio de ácidos graxos em dietas para novilhos Nelore em confinamento: Desempenho, características de carcaça e perfil de ácidos graxos. 2005. 76f. Tese (Doutorado) - Faculdade de Zootecnia e Engenharia de Alimentos, Universidade de São Paulo, Pirassununga.

VAN SOEST, P.J. Nutritional ecology of the ruminant. 2.ed. Ithaca: Constock Publishing, 1994. 476p.

VARGAS JR., F.M.; BONNECARRÈRE SANCHEZ, L.M.; PASCOAL, L.L. et al. Desempenho de novilhos de corte alimentados com dietas contendo quantidades crescentes de concentrado associado à forragem de aveia (Avena strigosa) tratada com ureia. Arq. Bras. Med. Vet. Zootec., Belo Horizonte, v.54, p.405-413, 2002

VELOSO, C.M.; RODRIGUEZ, N.M.; SAMPAIO, I.B.M. et al. pH e amônia ruminais, relação folhas:hastes e degradabilidade ruminal da fibra de forrageiras tropicais. Rev. Bras. Zootec., v.29, p.871879,2000

WEISS, W.P.; CONRAD, H.R.; ST. PIERRE, N.R. A theoretically based model for predicting total digestible nutrient values of forages and concentrates. Anim. Feed Sci. Technol., v.39, p.95-110, 1992. 